OPEN ACCESS

Edited by:

Jae Young Seong,

Korea University, South Korea

Reviewed by:

Gina Leinninger,

Michigan State University,

United States

Tamas Kozicz,

Mayo Clinic, United States

*Correspondence:

David A. Lovejoy

david.lovejoy@utoronto.ca

Specialty section:

This article was submitted to

Neuroendocrine Science,

a section of the journal

Frontiers in Neuroscience

Received: 19 February 2019 Accepted: 22 May 2019

Published: 31 July 2019

Citation:

Hogg DW, Husić M, Wosnick D,

Dodsworth T, D'Aquila AL and

Lovejoy DA (2019) Activity of the

Carboxy-Terminal Peptide Region

of the Teneurins and Its Role

in Neuronal Function and Behavior

in Mammals. Front. Neurosci. 13:581.

doi: 10.3389/fnins.2019.00581

\section{Activity of the Carboxy-Terminal Peptide Region of the Teneurins and Its Role in Neuronal Function and Behavior in Mammals}

David W. Hogg, Mia Husić, David Wosnick, Thomas Dodsworth, Andrea L. D'Aquila and David A. Lovejoy*

Department of Cell and Systems Biology, University of Toronto, Toronto, ON, Canada

Teneurin C-terminal associated peptides (TCAPS) are an evolutionarily ancient family of 40- to 41-residue bioactive peptides located on the extracellular end of each of the four teneurin transmembrane proteins. TCAP-1 may exist as a tethered peptide at the teneurin-1 carboxy end or as an independent peptide that is either released via post-transcriptional cleavage from its teneurin-1 pro-protein or independently expressed as its own mRNA. In neurons, soluble TCAP-1 acts as a paracrine factor to regulate cellular activity and neuroplastic interactions. In vitro studies indicate that, by itself, synthetic TCAP-1 promotes neuron growth and protects cells from chemical insult. In vivo, TCAP-1 increases hippocampal neuron spine density, reduces stressinduced behavior and ablates cocaine-seeking behaviors. Together, these studies suggest that the physiological effects of TCAP-1 are a result of an inhibition of corticotropin-releasing factor (CRF) activity leading to increased energy production. This hypothesis is supported by in vivo functional positron emissions tomography studies, which demonstrate that TCAP-1 significantly increases glucose uptake in rat brain. Complimentary in vitro studies show that enhanced glucose uptake is the result of TCAP-1-induced insertion of the glucose transporter into the neuronal plasma membrane, leading to increased glucose uptake and ATP production. Interestingly, TCAP-1-mediated glucose uptake occurs through a novel insulin-independent pathway. This review will focus on examining the role of TCAP on neuronal energy metabolism in the central nervous system.

Keywords: TCAP, teneurin, metabolism, glucose, stress, peptide evolution

\section{INTRODUCTION}

The teneurins are a family of type-II transmembrane glycoproteins that are widely expressed in the central nervous system (Baumgartner et al., 1994; Levine et al., 1994). They are involved in a number of cellular processes including the regulation of synaptic adhesion and maintenance of synaptic structures (Hong et al., 2012; Mosca et al., 2012; Boucard et al., 2014; Mosca and Luo, 2014; Li et al., 2018). Initially discovered in Drosophila, the teneurins were first thought to be related to the tenascin proteins. Baumgartner and colleagues were in search of Drosophila 
orthologs of the vertebrate tenascins when they identified two proteins and subsequently named them tenascin-like protein major (ten-m) and tenascin-like protein accessory (ten-a) (Baumgartner and Chiquet-Ehrismann, 1993; Baumgartner et al., 1994). At the same time, Levine et al. (1994) conducted a screen for novel phosphotyrosine-containing proteins when they identified a protein with homology to the tenascin family and named it odd $\mathrm{Oz}(\mathrm{Odz})$, as the odz mutant embryos did not contain odd-numbered body segments. Shortly after, a ten$\mathrm{m}$ homolog was identified in chicken and termed teneurin-1, due to its robust expression pattern in the nervous system (Minet et al., 1999). Since then, these proteins were found to be structurally and functionally distinct from the tenascins, and the name teneurin was adopted as the standard nomenclature to reflect their initial discovery and their neuronal expression patterns in various organisms (Tucker and Chiquet-Ehrismann, 2006). Subsequent homology studies revealed that the teneurins are present across most metazoans. Four homologs have been identified in vertebrates, whereas invertebrates contain only one copy, with the exception of insects, where two teneurin paralogs have been discovered (Baumgartner and ChiquetEhrismann, 1993; Baumgartner et al., 1994; Lovejoy et al., 2006; Chand et al., 2013a).

Teneurin genes encode proteins approximately 2800 amino acids in length that contain an intracellular amino terminal, a single transmembrane region and a large conserved extracellular carboxy terminal domain (Tucker et al., 2012). The four teneurin proteins (teneurin-1-4) exhibit a high degree of structural similarity to each other, as indicated by conservation of eight tenascin-type epidermal growth factor-like repeats, a cysteine rich region, five NHL domains and 26 tyrosine-aspartic acid repeats (Minet and Chiquet-Ehrismann, 2000; Kenzelmann et al., 2008; Tucker et al., 2012; Beckmann et al., 2013). Toward the distal end of the teneurin C-terminus is a short bioactive peptide sequence, termed teneurin C-terminal associated peptide (TCAP). The structure of the teneurins suggests that they evolved from a horizontal gene transfer event, which was likely mediated by a genomic internalization of a polymorphic proteinaceous toxin payload from a prokaryote donor to a choanoflagellate. This is corroborated by the widespread, yet highly conserved expression pattern of teneurins across various cell types (Drabikowski et al., 2005; Zhang et al., 2012; Chand et al., 2013b; Ferralli et al., 2018). Teneurins are most highly expressed within the central nervous system, where they form hetero- or homo-dimers to facilitate downstream signaling (Baumgartner et al., 1994; Kenzelmann et al., 2008), though their prevalence in other non-neuronal tissue types has been well-established (Baumgartner and Chiquet-Ehrismann, 1993; Baumgartner et al., 1994).

The TCAP region of the teneurins exhibits several characteristics of an independent peptide. It was first discovered during a screening for corticotropin-releasing factor (CRF)related homologs in a rainbow trout hypothalamic cDNA library using a hamster urocortin probe (Qian et al., 2004). A clone of the C-terminal region of rainbow trout teneurin-3 was isolated and termed TCAP-3. Subsequently TCAP-1, -2 and -4 were identified, totaling four highly conserved paralogs (Wang et al.,
2005). The TCAP sequence is $40-41$ amino acids in length and shares a structural similarity with CRF, calcitonin and other members of the Secretin superfamily of peptides (Lovejoy et al., 2006). TCAP shows widespread genetic expression in various brain regions, with in situ hybridization analyses showing TCAP mRNA expression in the murine olfactory bulb, cerebellum and brainstem (Wang et al., 2005). Though TCAP and teneurin share considerable overlap in expression patterns, the TCAPs are discretely expressed in some cortical regions that lack may teneurin expression, such as regions involved in the limbic system (Zhou et al., 2003; Wang et al., 2005; Chand et al., 2013a). These studies demonstrate that TCAP and teneurin may be differentially expressed, and ultimately suggest that TCAP processing may be independent from that of the teneurins.

\section{EVIDENCE OF TCAP AS A SMALL SOLUBLE PEPTIDE}

To determine if TCAP exists as a separate gene that produces a soluble peptide independent of teneurin, the existence of TCAPspecific mRNA was investigated by Northern blot (Chand et al., 2013a). Antisense probes to the terminal exon of all four mouse teneurins labeled the four full-length teneurin transcripts, as expected. However, in the case of teneurin-1 and -3 , shorter mRNA species less than 800 bases in length were readily identified. Sequence analysis of the teneurin-1 cDNA after $5^{\prime}$ RACE PCR-based cloning revealed a transcript of 485 bases, corresponding to the mRNA sequence encompassing two-thirds of the terminal teneurin-1 exon oriented toward the $3^{\prime}$ end (Chand et al., 2013a). The TCAP-1 mRNA is characterized by a short $5^{\prime}$ untranslated region, a peptide-encoding region of 357 bases corresponding to 118 translated residues and a $3^{\prime}$ untranslated region of about 74 or more bases. Within the peptide-encoding region additional postulated furin and basic residue cleavage sites were identified using the criteria suggested by Seidah and Chrétien (1997). These sites could potentially liberate smaller peptides of 107 and 41 residues. A $13 \mathrm{kDa}$ band was identified by Western blot, which could correspond to either a furin cleavage product or the full-length translation product of the TCAP-1 mRNA (Chand et al., 2013a). A smaller $5 \mathrm{kDa}$ band was shown in protein extracts from the vase tunicate, Ciona intestinalis, which could represent a soluble form of its 39-amino acid TCAP (Colacci et al., 2015; D’Aquila et al., 2017).

There is no evidence of a signal peptide in the putative translation product of the TCAP-1 mRNA, or in the equivalent TCAP regions of teneurin-2, -3, and -4 (Wang et al., 2005; Lovejoy et al., 2006; Chand et al., 2013a). Numerous bioactive peptide hormones and paracrine factors do not possess signal peptides. However, those belonging to the Secretin superfamily of ligands typically do contain such structures. Signal peptides facilitate entry into the vesicles of the secretory pathway, and peptides without this region typically remain in the cytosol. The full-length teneurins, however, do possess the hydrophobic transmembrane region that allow them to be inserted into the plasma membrane via fusion with secretory vesicles (Baumgartner et al., 1994; Levine et al., 1994). This 
distinction in cellular localization is apparent in the differential expression of immunoreactive teneurin-1, which is primarily found at the plasma membrane, and immunoreactive TCAP-1, which is confined to the cytosol (Chand et al., 2013a).

Taken together, these findings indicate that a soluble TCAP peptide could be liberated by direct cleavage from the teneurins, or in the case of TCAP-1 and possibly TCAP-3, transcribed as a smaller, independent mRNA that specifically encodes the TCAP region. The mechanism by which TCAP could be cleaved directly from the teneurins is not clear, though furin or prohormone convertases associated with secretory vesicles could be responsible for this (Seidah and Chrétien, 1997). However, this supposition remains mostly theoretical, as it has not been possible to confirm the existence of an endogenous soluble 40- or 41mer TCAP.

\section{IDENTIFICATION OF THE TENEURIN/TCAP RECEPTOR}

Although both teneurin and TCAP possess clear cellular action, the receptor mechanisms by which these effects occur were poorly understood until recently (Baumgartner et al., 1994; Levine et al., 1994; Qian et al., 2004). Early studies on the structure of TCAP showed that it contains several amino acid motifs found in peptides of comparable sizes belonging to the CRF and calcitonin families, suggesting a phylogenetic relationship between them (Lovejoy and Jahan, 2006; Lovejoy et al., 2006). Further evidence indicated that TCAP may be related to the Secretin peptide superfamily, and thus, its receptor may be part of the Secretin superfamily of GPCRs (Qian et al., 2004; Wang et al., 2005; Lovejoy and de Lannoy, 2013). However, receptor binding and activation studies showed that this is not the case, as Secretin GPCR family members had no significant interaction with TCAP-1 (Lovejoy and BarsyteLovejoy, unpublished observations).

In an attempt to further elucidate a putative receptor for TCAP-1, gene array studies investigating changes in gene expression of immortalized murine neuronal cells upon TCAP1 treatment were performed. These studies showed that TCAP-1-treated cells had higher expression of dystroglycan genes than vehicle-treated cells did (Chand et al., 2012), suggesting a functional relationship between the two proteins. The dystroglycans are transmembrane proteins associated with several receptor systems, particularly those of certain growth factors, integrins and other intercellular adhesion factors (Peng et al., 2008; Lombardi et al., 2017). Interestingly, no association between dystroglycans and Secretin GPCRs has been established to date. Fluorescence studies using a FITC-labeled variant of TCAP-1 and immunolabeled dystroglycan revealed that the two are, indeed, proximal to each other on the cell membrane. Moreover, TCAP-1 treatment induces activation of a MEK-ERK signal transduction system associated with the dystroglycans (Chand et al., 2012). Despite this, no direct evidence of binding between the two has been observed to date, indicating that they likely do not form a receptor-ligand pair, and may simply be parts of a larger intercellular complex.
Further research into teneurin binding partners has revealed a putative receptor for both teneurin and TCAP. Although full-length teneurins were previously shown to homo- and heterodimerize, leading to activation of downstream signaling cascades (Kenzelmann et al., 2007), the teneurins also bind to the GPCR Latrophilin-1 (LPHN1). Together, they form a trans-synaptic complex with both adhesion and cell signaling properties (Silva et al., 2011; Boucard et al., 2014; Vysokov et al., 2016). The LPHNs comprise a group of three GPCRs (LPHN13 ) that were first discovered in search for a calcium-independent receptor of $\alpha$-latrotoxin, the primary vertebrate toxin in black widow spider (genus Lactrodectus) venom (Davletov et al., 1996). Upon their discovery, the LPHNs were initially classified as Secretin GPCRs based on the high sequence similarities of their putative hormone-binding domain (HBD) with the signature HBDs of the Secretin GPCRs (Lelianova et al., 1997). They have since been reclassified as members of the Adhesion GPCR family due to their newly discovered adhesion functions and their long extracellular domains which contain several adhesion motifs (Fredriksson et al., 2003; Nordström et al., 2009). Recent phylogenetic analyses indicate that the Adhesion GPCR family is ancestral to the Secretin GPCR family, suggesting that Secretin GPCRs inherited their HBDs from their Adhesion GPCR ancestors (Nordström et al., 2009). If this is the case, other Adhesion GPCRs may also possess additional peptide ligands that have yet to be discovered. In this respect, TCAP may act as a model system to understand peptide-receptor interactions amongst the Adhesion GPCRs.

Further to these phylogenetic studies, several recent binding studies provide clear evidence that the TCAP region is required for teneurin-LPHN interaction. LPHN1 binds LPHN1-associated synaptic surface organizer (Lasso), a splice variant of teneurin2 comprised of the protein's distal C-terminus, including the TCAP-2 region (Silva et al., 2011). Full-length teneurin and Lasso both exhibit a high affinity with LPHN1, suggesting that TCAP itself might likewise bind with the LPHN family as an independent ligand. Deletion of the teneurin C-terminus reduces binding of teneurin with the extracellular domains of LPHN1 (Silva et al., 2011). Additionally, recent structural studies indicate that the teneurin extracellular domain forms a barrellike structure from which the TCAP-containing C-terminus protrudes (Jackson et al., 2018; Li et al., 2018). This conformation may make the TCAP portion of teneurin accessible to potential interacting partners, such as LPHN1, on adjacent cells and allow it to interact with said partners as either an active site of the full teneurin protein or independently as a cleavable peptide. Moreover, an interaction may occur directly between TCAP and LPHN1 at the LPHN1 HBD, as this is the region of peptide binding in Secretin GPCRs. It is also the most highly conserved region among the three LPHN isoforms and is involved in binding with other LPHN ligands such as $\alpha$-latrotoxin (Holz and Habener, 1998; Krasnoperov et al., 1999). Recent studies showed that a transgenically expressed TCAP-1 construct can be immunopreciptated with a transgenically expressed HBDcontaining fragment of LPHN1, indicating that an interaction does occur between these two proteins (Husić et al., 2018). In addition, over-expression of LPHN1 in HEK293 cells results 
in increased uptake of TCAP-1 and subsequent cytoskeletal reorganization consistent with what has been observed in other cell types upon TCAP-1 treatment, further indicating a functional interaction between these two proteins (Al Chawaf et al., 2007a; Chand et al., 2012; Husić et al., 2018).

\section{BIOACTIVITY OF TCAP-1}

Numerous studies have indicated potent bioactivity for synthetic TCAP-1. Treatment of Gn11 cells with multiple doses of TCAP1 showed that a low dose $(1 \mathrm{nM})$ leads to an increase in intracellular cAMP levels whereas a high dose (100 nM) decreases cAMP (Wang et al., 2005). Immortalized murine hypothalamic cells also display higher survivability under stress conditions when treated with TCAP-1, where TCAP-1 treatment led to increased total cell number and decreased necrotic cell number after $48 \mathrm{~h}$ in cells grown under high $\mathrm{pH}$ conditions (Trubiani et al., 2007). Likewise, cells exposed to peroxide exhibited decreased cell death when treated with TCAP-1, pointing to a role for the peptide in neuroprotection. In addition to this, TCAP-1 may also have actions in neuroplasticity, as it has potent effects on cytoskeletal dynamics. Treatment with TCAP1 increases $\beta$-actin and $\beta$-tubulin in murine immortalized hypothalamic cells and increases neurite outgrowth in a hippocampal cell line (Al Chawaf et al., 2007a; Tan et al., 2012). It also induces filamentous actin polymerization in a variety of cell lines through activation of a dystroglycan-associated MEK-ERK downstream signaling cascade (Chand et al., 2012; Husić et al., 2018).

These effects were further elucidated in an in vivo study utilizing intracerebroventricular injection of TCAP-1 under unstressed and restraint conditions. Under unstressed conditions, TCAP-1 decreased dendritic branching while under stressed conditions it increased dendritic branching (Al Chawaf, 2008). Although the mechanism is still unknown, these results provide evidence that TCAP-1 plays a role in neuroplasticity.

Immunohistochemical analysis has revealed that immunoreactive TCAP-1 is present within the limbic system, particularly in the areas associated with regulation of the behavioral stress response, such as the pyramidal layer of the hypothalamus and the basolateral nucleus of the amygdala (Tan et al., 2012). Neurons in these regions are morphologically plastic and can change in response to stimuli such as stress and learning (Tan et al., 2009, 2011; Chen et al., 2013). The effects of TCAP-1 on stress-related behavior have been observed using several methodologies including the acoustic startle response (ASR), an indicator of anxiety and a test of reflexive fear response (Rotzinger et al., 2010). Through these studies, two major bioactive attributes of TCAP-1 have been identified: its neuromodulatory effects and its regulation of the CRF-induced stress response. In one such study, rats were separated based on their baseline ASR response prior to any treatment, and subsequently treated intracerebroventricularly with TCAP-1 (Wang et al., 2005). Rats with a low baseline ASR response exhibited an increase of in response upon TCAP-1 treatment. In contrast, rats with a high baseline ASR showed an attenuated response after treatment with TCAP-1. TCAP-1 was also shown to induce long-term attenuation of the stress response, as rats had a $50 \%$ reduction in ASR up to 15 days after TCAP-1 treatment (Wang et al., 2005). Moreover, pretreatment with TCAP-1 is able to modulate CRF-induced stress responses in several behavioral paradigms including ASR, elevated plus maze and open field tests (Al Chawaf et al., 2007b; Tan et al., 2008; Rotzinger et al., 2010). CRF-induced cocaine reinstatement is also reduced in rats given TCAP-1 pre-treatment (Kupferschmidt et al., 2011; Erb et al., 2014). These studies highlight the role TCAP-1 has in regulating CRF-associated behaviors related to anxiety and depression in rodent models (Figure 1).

\section{ROLE OF ENERGY METABOLISM BY TCAP}

In both animal and cell models, synthetic TCAP-1 activates several processes that necessitate increased energy production. This includes protection of neurons against alkaline chemical insults and cell death (Trubiani et al., 2007), stimulation of neurite outgrowth, reorganization of cytoskeletal elements in neurons (Al Chawaf et al., 2007a; Tan et al., 2011; Chand et al., 2012), and modulation of stress-related behaviors (Wang et al., 2005; Al Chawaf et al., 2007b; Tan et al., 2008). These actions are energetically costly, indicating that TCAP-1 may also stimulate energy production to maintain them, as cellular supply of ATP must meet cellular energy demand.

Glucose is the preferred energy substrate in brain, and a steady supply is critical for neuronal function; however, neurons have a limited capacity to store glucose intracellularly. Therefore, a TCAP-1-mediated increase in intracellular glucose would indicate that TCAP-1 can also stimulate cellular energy metabolism. In a study using functional positron emission

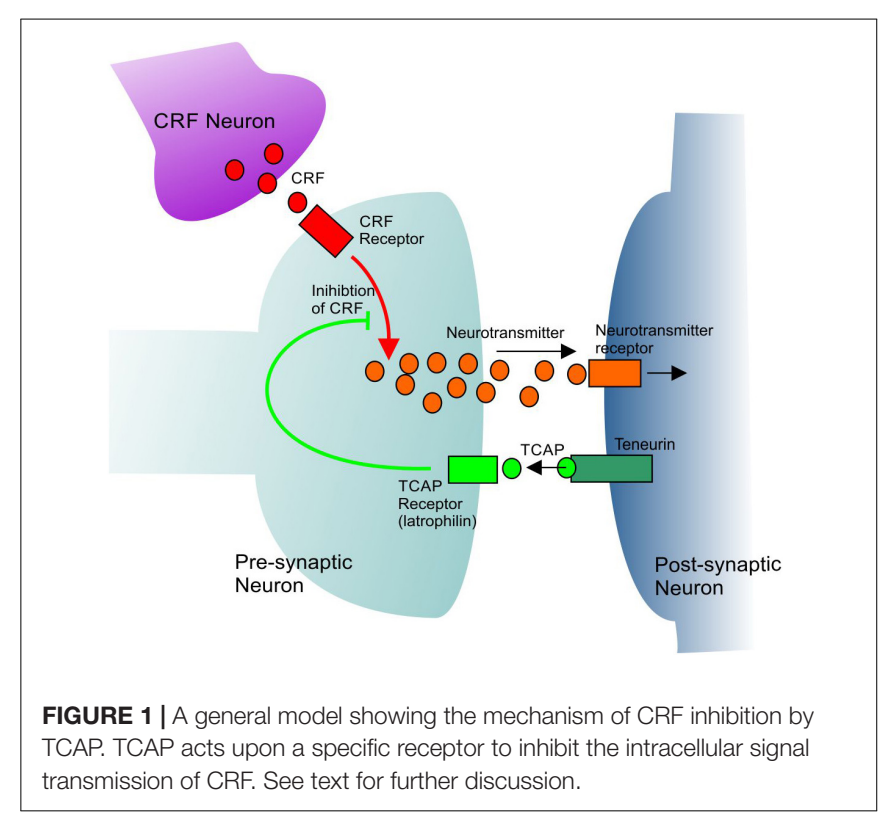


tomography, a single subcutaneous injection of TCAP-1 induced a significant increase in ${ }^{18} \mathrm{~F}$-deoxyglucose uptake into the brain 3 days post-treatment (Hogg et al., 2018). Glucose uptake was highest in the frontal cortex and subcortical regions, although it occurred throughout the cortical regions. In addition, a single injection of TCAP-1 decreased whole animal blood glucose by $35-40 \%$, with a concomitant decrease in serum insulin and an increase in serum glucagon. This pattern mimics the effect of insulin on blood glucose and glucagon, demonstrating that TCAP-1 alters whole animal glucose metabolism. Similar results were obtained in GotoKakizaki rats, a type-II diabetic insulin-insensitive pathological model, suggesting that TCAP-1-stimulated glucose uptake is independent of the insulin system.

In confirmation of these studies, TCAP-1 also increases glucose uptake in a hypothalamic neuron cell model. In these cells, TCAP-1 increased uptake of $\left[{ }^{3} \mathrm{H}\right.$ - $] 2$-deoxyglucose, a non-hydrolysable form of glucose, by $50 \%$ following 60 and $90 \mathrm{~min}$ of treatment. This profile differed from that of insulin, which induced uptake at $30 \mathrm{~min}$ post-treatment, further indicating that TCAP-1 regulates glucose uptake independently of insulin. This was confirmed when insulin- and TCAP-1mediated glucose uptake were assessed in the presence and absence of a depolarizing stimulus. Insulin-mediated glucose uptake requires membrane depolarization for glucose transporter (GLUT) insertion into the plasma membrane (Uemura and Greenlee, 2006). Unlike insulin, TCAP-1-mediated glucose uptake occurrs in the absence of membrane depolarization events (Hogg et al., 2018). The timeline and depolarization-independent nature of TCAP-1-induced glucose uptake indicates that TCAP-1 activates a signaling mechanism distinct from that of insulinmediated glucose uptake.

Glucose uptake into neurons occurs by faciltated diffusion through GLUTs, and is dependent on the plasma membrane expression of GLUTs and the diffusion gradient of glucose into the cell. The actions of TCAP-1 are consistent with this mechanism. TCAP-1 increases GLUT3 transport to the plasma membrane of a hypothalamic neuronal model by $37.5 \%$ within $1 \mathrm{~h}$, where the increase is maintained for up to $3 \mathrm{~h}$ post-treatment (Hogg et al., 2018). In addition, TCAP-1 increases GLUT3 immunoreactivity by $\sim 250 \%$ in the growth cones of extending neurites $1-2 \mathrm{~h}$ post-treatment. Moreover, TCAP-1 does not significantly increase membrane expression of GLUT1 or GLUT4, indicating that TCAP-1induced glucose uptake likely occurs specifically through a GLUT3-mediated process. GLUT3 is the primary glucose transporter in brain, whereas the GLUT1 transporters are typically located in endothelial cells of the blood-brain barrier, and the GLUT4 transporters are highly expressed in skeletal muscle and adipose tissue and known to be insulin-dependent (Shepherd et al., 1992; Haber et al., 1993; Choeiri et al., 2002; Airley and Mobasheri, 2007).

Increases in intracellular glucose importation stimulate cellular energy metabolism. TCAP-1 significantly increases intracellular ATP turnover in a dose-dependent manner in an immortalized neuronal cell line, demonstrating that TCAP1-mediated glucose uptake does, indeed, stimulate neuronal energy metabolism (Hogg et al., 2018). This increase in intracellular ATP turnover is likely the result of stimulation of aerobic energy-producing pathways, as TCAP-1 also decreases cellular lactate concentrations. Cellular pyruvate concentrations likewise decreased, indicating the metabolic pathway favors producing pyruvate for oxidative energy production. Previous studies have demonstrated that TCAP1 can significantly increase catalase, superoxide dismutase and the superoxide dismutase copper chaperone (Trubiani et al., 2007), reducing intracellular reactive oxygen species. If TCAP-1 is increasing mitochondrial activity, there would be a consequential increase of reactive oxygen species production, thus the TCAP-1 system may have evolved a mechanism to compensate this. Taken together, these data demonstrate that TCAP-1 is a functional component of the teneurin protein that regulates glucose uptake and neuronal energetics in the rodent brain.

\section{CONCLUSION}

Teneurin C-terminal associated peptide represents a bioactive region of the teneurin proteins that may act as a tethered ligand or a distinct peptide that is either cleaved from the full-length teneurin protein or expressed independently (Chand et al., 2013a). TCAP-1 has several energetically favorable functions, and increases uptake of glucose into the rodent brain (Hogg et al., 2018). This indicates that it can act to increase energy availability, allowing for its other implicated functions to take place. The exact mechanism by which TCAP1 acts is yet to be elucidated; however, TCAP-1-mediated glucose uptake appears to be independent of insulin. Although further studies are required to tease out the precise signaling cascade that TCAP-1 induces to facilitate increased neuronal glucose uptake via GLUT3, the current studies presented in this review reveal a novel and essential function of this peptide family, further supporting TCAP as a critical stressresponse regulator.

\section{AUTHOR CONTRIBUTIONS}

$\mathrm{DH}$ : analysis of energy metabolism and description of key studies. MH: interpretation of receptor interaction and associated experiments, review and editing of the manuscript. DW: overview of aerobic studies on TCAP and associated literature. TD: molecular biology of TCAP receptor interactions and associated literature. AD'A: development of key experiments associated with TCAP action. DL: supervision of research program and overview of the manuscript.

\section{FUNDING}

The studies described in the manuscript have been funded by the Natural Sciences and Engineering Research Council (NSERC) Canada, and Protagenic Therapeutics, Inc., United States. 


\section{REFERENCES}

Airley, R. E., and Mobasheri, A. (2007). Hypoxic regulation of glucose transport, anaerobic metabolism and angiogenesis in cancer: novel pathways and targets for anticancer therapeutics. Chemotherapy 53, 233-256. doi: 10.1159/ 000104457

Al Chawaf, A. (2008). Teneurin C-terminal Associated Peptide (TCAP): Molecular and Cellular Characterization of in vivo and in vitro Neuromodulatory Effects of TCAP-1. PhD thesis. Toronto: University of Toronto.

Al Chawaf, A., St. Amant, K., Belsham, D., and Lovejoy, D. A. (2007a). Regulation of neurite growth in immortalized mouse hypothalamic neurons and rat hippocampal primary cultures by teneurin C-terminal associated peptide-1. Neuroscience 144, 1241-1254. doi: 10.1016/j.neuroscience.2006.09.062

Al Chawaf, A., Xu, K., Tan, L., Vaccarino, F. J., Lovejoy, D. A., and Rotzinger, S. (2007b). Corticotropin-releasing factor (CRF)-induced behaviours are modulated by intravenous administration of teneurin C-terminal associated peptide-1 (TCAP-1). Peptides 28, 1406-1415. doi: 10.1016/j.peptides.2007.05. 014

Baumgartner, S., and Chiquet-Ehrismann, R. (1993). Tena, a Drosophila gene related to tenascin shows selective transcript localization. Mech. Dev. 40, 165176. doi: 10.1016/0925-4773(93)90074-8

Baumgartner, S., Martin, D., Hagios, C., and Chiquet-Ehrismann, R. (1994). Ten$\mathrm{m}$, a Drosophila gene related to tenascin is a new pair-rule gene. EMBO J. 13, 3728-3740. doi: 10.1002/j.1460-2075.1994.tb06682.x

Beckmann, J., Schubert, R., Chiquet-Ehrismann, R., and Müller, D. J. (2013). Deciphering teneurin domains that facilitate cellular recognition, cell-cell adhesion, and neurite outgrowth using atomic force microscopy-based singlecell force spectroscopy. Nano Lett. 12, 2937-2946. doi: 10.1021/nl4013248

Boucard, A., Maxeiner, S., and Sudhof, T. C. (2014). Latrophilins function as heterophilic cell-adhesion molecules by binding to teneurins: regulation by alternative splicing. J. Biol. Chem. 289, 387-402. doi: 10.1074/jbc.M113.50 4779

Chand, D., Cassati, C. A., de Lannoy, L., Song, L., Kollara, A., Barsyte-Lovejoy, D., et al. (2013a). C-terminal processing of the teneurin proteins: independent actions of a teneurin C-terminal associated peptide in hippocampal cells. Mol. Cell. Neurosci. 52, 38-50. doi: 10.1016/j.mcn.2012.09.006

Chand, D., de Lannoy, L., Tucker, R., and Lovejoy, D. A. (2013b). Origin of chordate peptides by horizontal gene transfer in early metazoans and protists: evolution of the teneurin C-terminal associated peptides (TCAP). Gen. Comp. Endocrinol. 188, 144-150. doi: 10.1016/j.ygcen.2013.02.006

Chand, D., Song, L., de Lannoy, L., Barsyte-Lovejoy, D., Ackloo, S., Boutros, P. C., et al. (2012). C-terminal region of teneurins-1 co-localizes with dystroglycan and modulates cytoskeletal organization through an extracellular signalregulated kinase-dependent stathmin- and filamin A-mediated mechanism in hippocampal cells. Neuroscience 219, 225-270. doi: 10.1016/j.neuroscience. 2012.05.069

Chen, Y., Xu, M., Almeida, R., and De Lovejoy, D. A. (2013). Teneurin C-terminal associated peptides (TCAP): modulators of corticotropin-releasing factor (CRF) physiology and behavior. Front. Neurosci. 7:166. doi: 10.3389/fnins.2013. 00166

Choeiri, C., Staines, W., and Messier, C. (2002). Immunohistochemical localization and quantification of glucose transporters in the mouse brain. Neuroscience 111, 19-34. doi: 10.1016/s0306-4522(01)00619-4

Colacci, M., De Almeida, R., Chand, D., Lovejoy, S. R., Septon, D., Vercaemer, B., et al. (2015). Characterization of the teneurin C-terminal associated peptide (TCAP) in the vase tunicate, Ciona intestinalis: a novel peptide system associated with energy metabolism and reproduction. Gen. Comp. Endocrinol. 216, 161-170. doi: 10.1016/j.ygcen.2015.01.021

D’Aquila, A. L., Hsieh, A. H.-R., Hsieh, A. H.-M., De Almeida, R., Lovejoy, S. R., and Lovejoy, D. A. (2017). Expression and actions of corticotropin-releasing factor/diuretic hormone-like peptide (CDLP) and teneurin C-terminal associated peptide (TCAP) in the vase tunicate, Ciona intestinalis: antagonism of the feeding response. Gen. Comp. Endocrinol. 246, 105-115. doi: 10.1016/j. ygcen.2016.06.015

Davletov, B. A., Shamotienko, O. G., Lelianova, V. G., Grishin, E. V., and Ushkaryov, Y. A. (1996). Isolation and biochemical characterization of a CA2+independent alpha-latrotoxin-binding protein. J. Biol. Chem. 271, 23239-23245. doi: $10.1074 /$ jbc.271.38.23239
Drabikowski, K., Trzebiatowska, A., and Chiquet-Ehrismann, R. (2005). ten-1, an essential gene for germ cell development, epidermal morphogenesis, gonad migration and neurinal pathfinding in Caenorhabditis elegans. Dev. Biol. 282, 27-38. doi: 10.1016/j.ydbio.2005.02.017

Erb, S., McPhee, M., Brown, Z. J., Kupferschmidt, D. A., Song, L., and Lovejoy, D. A. (2014). Repeated intravenous administrations of teneurin-C terminal associated peptide (TCAP)-1 attenuates reinstatement of cocaine seeking by corticotropin-releasing factor (CRF) in rats. Behav. Brain Res. 269, 1-5. doi: 10.1016/j.bbr.2014.04.013

Ferralli, J., Tucker, R. P., and Chiquet-Ehrismann, R. (2018). The teneurin C-terminal domain possesses nuclease activity and is apoptogenic. Biol. Open 7:bio031765. doi: 10.1242/bio.031765

Fredriksson, R., Lagerström, M. C., Lundin, L. G., and Schiöth, H. B. (2003). The G-protein-coupled receptors in the human genome form five main families. Phylogenetic analysis, paralogon groups, and fingerprints. Mol. Pharmacol. 63, 1256-1272. doi: 10.1124/mol.63.6.1256

Haber, R. S., Weinstein, S. P., O’Boyle, E., and Morgello, S. (1993). Tissue distribution of the human GLUT3 glucose transporter. Endocrinology 132, 2538-2543. doi: 10.1210/en.132.6.2538

Hogg, D. W., Chen, Y., D’Aquila, A. L., Xu, M., Husić, M., Tan, L. A., et al. (2018). A novel role of the corticotropin-releasing hormone $(\mathrm{CRH})$ regulating peptide, teneurin-1 C-terminal associated peptide (TCAP-1), on glucose uptake into the brain. J Neuroendocrinol. 30:e12579. doi: 10.1111/jne.12579

Holz, G. G., and Habener, J. F. (1998). Black widow spider alpha-latrotoxin: a presynaptic neurotoxin that shares structural homology with the glucagonlike peptide-1 family of insulin secretagogic hormones. Comp. Biochem. Physiol. B Biochem. Mol. Biol. 121, 177-184. doi: 10.1016/s0305-0491(98)10 088-3

Hong, W., Mosca, T. J., and Luo, L. (2012). Teneurins instruct synaptic partner matching in an olfactory map. Nature 484, 201-207. doi: 10.1038/nature10926

Husić, M., Barsyte-Lovejoy, D., and Lovejoy, D. A. (2018). Teneurin C-terminal associated peptide (TCAP-1) and latrophilin interaction in HEK293 cells: evidence for modulation of intercellular adhesion. Front. Endocrinol. 10:22. doi: 10.3389/fendo.2019.00022

Jackson, V. A., Meijer, D. H., Carrasquero, M., van Bezouwen, L. S., Lowe, E. D., Kleanthous, C., et al. (2018). Structures of Teneurin adhesion receptors reveal an ancient fold for cell-cell interaction. Nat. Commun. 9:1079. doi: 10.1038/ s41467-018-03460-0

Kenzelmann, D., Chiquet- Ehrisman, R., and Tucker, R. P. (2007). Teneurins, a transmembrane protein family involved in cell communication during neuronal development. Cell. Mol. Life Sci. 64, 1452-1456. doi: 10.1007/s00018007-7108-9

Kenzelmann, D., Chiquet-Ehrismann, R., Leachman, N. T., and Tucker, R. P. (2008). Teneurin-1 is expressed in intercommected regions of the developing brain and is processed in vivo. BMC Dev. Biol. 8:30. doi: 10.1186/1471-2 13X-8-30

Krasnoperov, V., Bittner, M. A., Holz, R. W., Chepurny, O., and Petrenko, A. G. (1999). Structural requirements for alpha-latrotoxin binding and alphalatrotoxin-stimulated secretion. A study with calcium-independent receptor of alpha-latrotoxin (CIRL) deletion mutants. J. Biol. Chem. 274, 3590-3596. doi: 10.1074/jbc.274.6.3590

Kupferschmidt, D. A., Lovejoy, D. A., Rotzinger, S., and Erb, S. (2011). Teneurin C-terminal associated peptide-1 blocks the effects of corticotropin-releasing factor on reinstatement of cocaine-seeking and on cocaine-induced behavioural sensitization. Br. J. Pharmacol. 162, 574-583. doi: 10.1111/j.1476-5381.2010. 01055.x

Lelianova, V. G., Davletov, B. A., Sterling, A., Rahman, M. A., Grishin, E. V., Totty, N. F., et al. (1997). Alpha-latrotoxin receptor, latrophilin, is a novel member of the secretin family of G protein-coupled receptors. J. Biol. Chem. 272, 21504-21508. doi: 10.1074/jbc.272.34.21504

Levine, A., Bashan-Ahrend, A., Budai-Hadrian, O., Gartenberg, D., Menasherow, S., and Wides, R. (1994). Odd Oz: a novel Drosophila pair rule gene. Cell 77, 587-598. doi: 10.1016/0092-8674(94)90220-8

Li, J., Shalev-Benami, M., Sando, R., Jiang, X., Kibrom, A., Wang, J., et al. (2018). Structural basis for teneurin function in circuit-wiring: a toxin motif at the synapse. Cell 173, 735-748. doi: 10.1016/j.cell.2018.03.036

Lombardi, L., Persiconi, I., Gallo, A., Hoogenraad, C. C., and De Stefano, M. E. (2017). NGF-dependent axon growth and regeneration are altered in 
sympathetic neurons of dystrophic mdx mice. Mol. Cell. Neurosci. 80, 1-17. doi: 10.1016/j.mcn.2017.01.006

Lovejoy, D. A., Al Chawaf, A., and Cadinouche, M. Z. (2006). Teneurin C-terminal associated peptides: an enigmatic family of neuropeptides with sstructural similarity to the corticotropin-releasing factor and calcitonin families of peptides. Gen. Comp. Endocrinol. 148, 299-305. doi: 10.1016/j.ygcen.2006. 01.012

Lovejoy, D. A., and de Lannoy, L. (2013). Evolution and phylogeny of the corticotropin-releasing factor (CRF) family of peptides: expanson and specialization in vertebrates. J. Chem. Neuroanat. 54, 50-56. doi: 10.1016/j. jchemneu.2013.09.006

Lovejoy, D. A., and Jahan, S. (2006). Phylogeny of the corticotropin-releasing factor family of peptides in the metazoa. Gen. Comp. Endocrinol. 146, 1-8. doi: 10.1016/j.ygcen.2005.11.019

Minet, A. D., and Chiquet-Ehrismann, R. (2000). Phylogenetic analysis of teneurin genes and comparison to the rearrangement hot spot elements of E. coli. Gene 257, 87-97. doi: 10.1016/s0378-1119(00)00388-7

Minet, A. D., Rubin, B. P., Tucker, R. P., Baumgartner, S., and Chiquet-Ehrismann, R. (1999). Teneurin-1, a vertebrate homologue of the Drosophila pair-rule gene ten- $\mathrm{m}$, is a neuronal protein with a novel type of heparin-binding domain. J. Cell Sci. 112, 2019-2032.

Mosca, T. J., Hong, W., Dani, V. S., Favaloro, V., and Luo, L. (2012). Trans-synaptic Teneurin signalling in neuromuscular synapse organization and target choice. Nature 484, 237-241. doi: 10.1038/nature10923

Mosca, T. J., and Luo, L. (2014). Synaptic organization of the Drosophila antennal love and its regulation by the Teneurins. eLife 3:e03726. doi: 10.7554/eLife. 03726

Nordström, K. J., Lagerström, M. C., Wallér, L. M., Fredriksson, R., and Schiöth, H. B. (2009). The Secretin GPCRs descended from the family of adhesion GPCRs. Mol. Biol. Evol. 26, 71-84. doi: 10.1093/molbev/msn228

Peng, H., Shah, W., Holland, P., and Carbonetto, S. (2008). Integrins and dystroglycan regulate astrocyte wound healing: the integrin betal subunit is necessary for process extension and orienting the microtubular network. Dev. Neurobiol. 68, 559-574. doi: 10.1002/dneu.20593

Qian, X., Barsyte-Lovejoy, D., Wang, L., Chewpoy, B., Gautam, N., Al Chawaf, A., et al. (2004). Cloning and characterization of teneurin C-terminus associated peptide (TCAP)-3 from the hypthalamus of an adult rainbow trout (Onchorhynchus mykiss). Gen. Comp. Endocrinol. 137, 205-216. doi: 10.1016/ s0016-6480(04)00051-6

Rotzinger, S., Lovejoy, D. A., and Tan, L. A. (2010). Behavioral effects of neuropeptides in rodent models of depression and anxiety. Peptides 31, 736-756. doi: 10.1016/j.peptides.2009.12.015

Seidah, N. G., and Chrétien, M. (1997). Eukaryotic protein processing: endoproteolysis of precursor proteins. Curr. Opin. Biotech. 8, 602-607. doi: 10.1016/s0958-1669(97)80036-5

Shepherd, P. R., Gould, G. W., Colville, C. A., McCoid, S. C., Gibbs, E. M., and Kahn, B. B. (1992). Distribution of GLUT3 glucose transporter protein in human tissues. Biochem. Bioph. Res. Commun. 188, 149-154. doi: 10.1016/ 0006-291x(92)92362-2

Silva, J. P., Lelianova, V. G., Ermolyuk, Y. S., Vysokov, N., Hitchen, P. G., Berninghausen, O., et al. (2011). Latrophilin 1 and its endogenous ligand Lasso/teneurins-2 form a high-affinity transsynaptic receptor pair with signaling capabilities. Proc. Natl. Acad. Sci. U.S.A. 108, 12113-12118. doi: $10.1073 /$ pnas. 1019434108

Tan, L., Xu, K., Vaccarino, F., Lovejoy, D. A., and Rotzinger, S. (2008). Repeated intracerebral teneurin C-terminal associated peptide (TCAP)-1 injections produce enduring changes in behavioral responses to corticotropin-releasing factor (CRF) in rat models of anxiety. Behav. Brain Res. 188, 195-200. doi: $10.1016 /$ j.bbr.2007.10.032
Tan, L. A., Al Chawaf, A., Vaccarino, F. J., Boutros, P. C., and Lovejoy, D. A. (2011). Teneurin C-terminal associated peptide (TCAP)-1 modulates dendritic morphology in hippocampal neurons and decreases anxiety-like behaviours in rats. Physiol. Behav. 104, 199-204. doi: 10.1016/j.physbeh.2011.03.015

Tan, L. A., Chand, D., De Almeida, R., Xu, M., De Lannoy, L., and Lovejoy, D. A. (2012). Modulation of neuroplastic changes and corticotropin-releasing factorassociated behavior by a phylogenetically ancient and conserved peptide family. Gen. Comp. Endocrinol. 176, 309-313. doi: 10.1016/j.ygcen.2011.11.011

Tan, L. A., Xu, K., Vaccarino, F. J., Lovejoy, D. A., and Rotzinger, S. (2009). Teneurin C-terminal associated peptide (TCAP)-1 attenuates corticotropinreleasing factor (CRF)-induced c-Fos expression in the limbic system and modulates anxiety behavior in male Wistar rats. Behav. Brain Res. 201, 198-206. doi: 10.1016/j.bbr.2009.02.013

Trubiani, G., Al Chawaf, A., Belsham, D. D., Barsyte-Lovejoy, D., and Lovejoy, D. A. (2007). Teneurin carboxy (C)-terminal associated peptide-1 inhibits alkalosis-associated necrotic neuronal death by stimulating superoxide dismutase and catalase activity in immortalized mouse hypothalamic cells. Brain Res. 1176, 27-36. doi: 10.1016/j.brainres.2007.07.087

Tucker, R. P., Beckmann, J., Leachman, N. T., Schöler, J., and Chiquet-Ehrismann, R. (2012). Phylogenetic analysis of the teneurins: conserved features and premetazoan ancestry. Mol. Biol. Evol. 29, 1019-1029. doi: 10.1093/molbev/ msr271

Tucker, R. P., and Chiquet-Ehrismann, R. (2006). Teneurins: a conserved family of transmembrane proteins involved in intercellular signalling during development. Dev. Biol. 290, 237-245. doi: 10.1016/j.ydbio.2005. 11.038

Uemura, E., and Greenlee, H. W. (2006). Insulin regulates neuronal glucose uptake by promoting translocation of glucose transporter GLUT3. Exp. Neurol. 198, 48-53. doi: 10.1016/j.expneurol.2005.10.035

Vysokov, N. V., Silva, J. P., Lelianova, V. G., Ho, C., Djamgoz, M. B., Tonevitsky, A. G., et al. (2016). The mechanism of regulated release of Lasso/Teneurin-2. Front. Mol. Neurosci. 9:59. doi: 10.3389/fnmol.2016.00059

Wang, L., Rotzinger, S., Al Chawaf, A., Elias, C. F., Barsyte-Lovejoy, D., Qian, X., et al. (2005). Teneurin proteins possess a carboxy terminal sequence with neuromodulatory activity. Brain Res. Mol. Brain Res. 133, 253-265. doi: 10. 1016/j.molbrainres.2004.10.019

Zhang, D., deSouza, R. F., Anantharaman, V., Iyer, L. M., and Aravind, L. (2012). Polymorphic toxin systems: comprehensive characterization of trafficking modes, mechanism of action, immunity and ecology using comparative genomics. Biol. Direct. 7:18. doi: 10.1186/1745-6150-7-18

Zhou, X. H., Brandau, O., Feng, K., Oohashi, T., Ninomiya, Y., Rauch, U., et al. (2003). The murine Ten-m/Odz genes show distinct but overlapping expression patterns during development and in adult brain. Gene Expr. Patterns 3, 397-405. doi: 10.1016/s1567-133x(03)00087-5

Conflict of Interest Statement: DL is a co-founder of Protagenic Therapeutics, Inc., a commercial entity that may have interests in the findings of these studies.

The remaining authors declare that the research was conducted in the absence of any commercial or financial relationships that could be construed as a potential conflict of interest.

Copyright (c) 2019 Hogg, Husić, Wosnick, Dodsworth, D'Aquila and Lovejoy. This is an open-access article distributed under the terms of the Creative Commons Attribution License (CC BY). The use, distribution or reproduction in other forums is permitted, provided the original author(s) and the copyright owner(s) are credited and that the original publication in this journal is cited, in accordance with accepted academic practice. No use, distribution or reproduction is permitted which does not comply with these terms. 